Brit. J. industr. Med., 1956, 13, 131.

\title{
CONSISTENCY AND CAR DRIVING SKILL
}

\author{
BY \\ R. E. F. LEWIS \\ From the Medical Research Council, Applied Psychology Research Unit, Cambridge
}

(RECEIVED FOR PUBLICATION JULY 29, 1955)

It seems likely that when a man is learning a new skill he tends to correct for mistakes by going too far in the opposite direction. Lashley (1951) mentions for example that after an inexperienced typist has made an error he may even over-compensate to the extent of repeating the letter previously omitted. The learner proceeds by a series of oscillations about the ideal which may itself vary with the individual when skilled manual behaviour is under consideration. Improvement in skill may be accompanied by a reduction in the size of these oscillations. For instance, in learning to ride a bicycle, the wild wobble is gradually replaced by almost invisible movements. Bartlett (1951) has remarked that " notable irregularities in a pattern of control movements are the surest sign of awkwardness in skill". Again, with reference to the skilled operator, "What is impressive is the absence of any appearance of hurry. There is no jerkiness or snatching, no obvious racing to catch up in one part and forced sauntering to make up in another " (Bartlett, 1947).

Ashby (1952) has shown how a homeostatic machine when disturbed will oscillate in decreasing rhythms until it has established a new equilibrium with the stimulus, when its response will be minimal ; " under constant stimulation the response has diminished". It is probable that there are some resemblances between the mechanisms of the human learning process and such machines.

If we can examine the performance of skilled and unskilled people on a given task the most noticeable difference might be that the skilled performance is sufficiently regular to be reproduced on another occasion provided that extraneous random factors can be kept at a minimum. When dealing with an activity such as driving a car, it is difficult to obtain any absolute criterion of errors, but any lack of consistency within the work from a given man can be directly studied. The following experiments consider the performance of groups of drivers, classified as skilled or unskilled, during a standard driving task. This involved taking corners in the absence of any other traffic. Records were kept of the performance of these $\mathbf{3 0}$ men over the course on two different occasions separated by six weeks. Particular attention was paid to the acceleration records. While there can be no ideal method of taking such a course, it seems likely that the skilled driver will have a pattern of behaviour for a given situation which experience has taught him is the best. Thus the skilled driver may show a smoother curve of acceleration and deceleration and a further attempt may lead to a pattern of activity which resembles the previous curve.

\section{Procedure}

The Test Course.-An airfield with runways forming an equilateral triangle and having a good driving surface was used for the trials. The inner side of the runways (15 $\mathrm{ft}$. wide lanes) formed the "roads" ; the limits of the road at two corners around each of which a turn of 120 degrees had to be made, were marked with surveyors' posts (Fig. 1). At a point 150 yards before and after

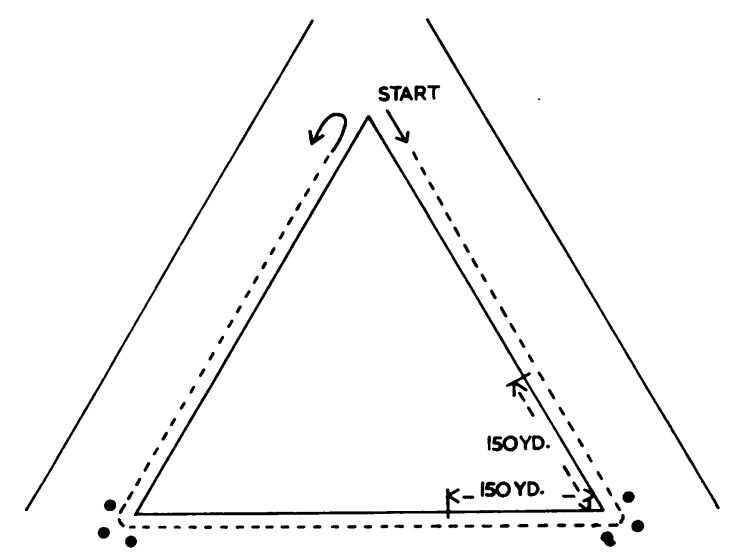

Fig. 1.-Test corners through $120^{\circ}$ on airfield runways. 
each corner a mark, recognizable by the passing observer, was painted on the runway edge.

Apparatus.-The experimental car was a series E, 1947 Morris 10 Saloon. A recording apparatus was constructed to enable a photograph to be taken by the forward-facing single-shot camera once every five yards of distance travelled, regardless of speed. (This camera viewed through the windscreen and each frame showed the dashboard instruments, including a Tapley performance meter* set to zero on level ground, see Fig. 2.)

Subjects.-The Chief Driving Instructor of the Essex County Police Advanced Driving School was asked to select three groups of drivers.

Ten Skilled Police Driving Instructors or Motor Patrol Drivers.-These drivers in Group 1 were known to possess exceptional driving ability and were considered to represent the best standards of police driving.

Ten Skilled Rally Drivers, not Police Trained.-The skilled men in this group were keen car club drivers. They were enthusiastic enough to spend most week-ends practising for or participating in club or rally events, in which behaviour and skill played an important part.

They cannot be regarded as having quite the polish of the skilled police driver, but as a group they represent the normal civilian driving community at a level " well above average".

Ten Unskilled Drivers.-All of these drivers had, however, driven for at least three years ; the unskilled men were considered, purely on opinion and not because of any accident record, to drive in a manner well below the average. They were mainly employed as civilians in duties associated with vehicle maintenance and drove light transport in the course of their work.

Expcrience.-All the drivers were men and their ages ranged between 21 and 54 years. The police group

* The Tapley performance meter is a damped accelerometer; or nearly one-third " $\mathrm{g}$ ". The instrument was read to the nearest $10 \mathrm{lb}$.

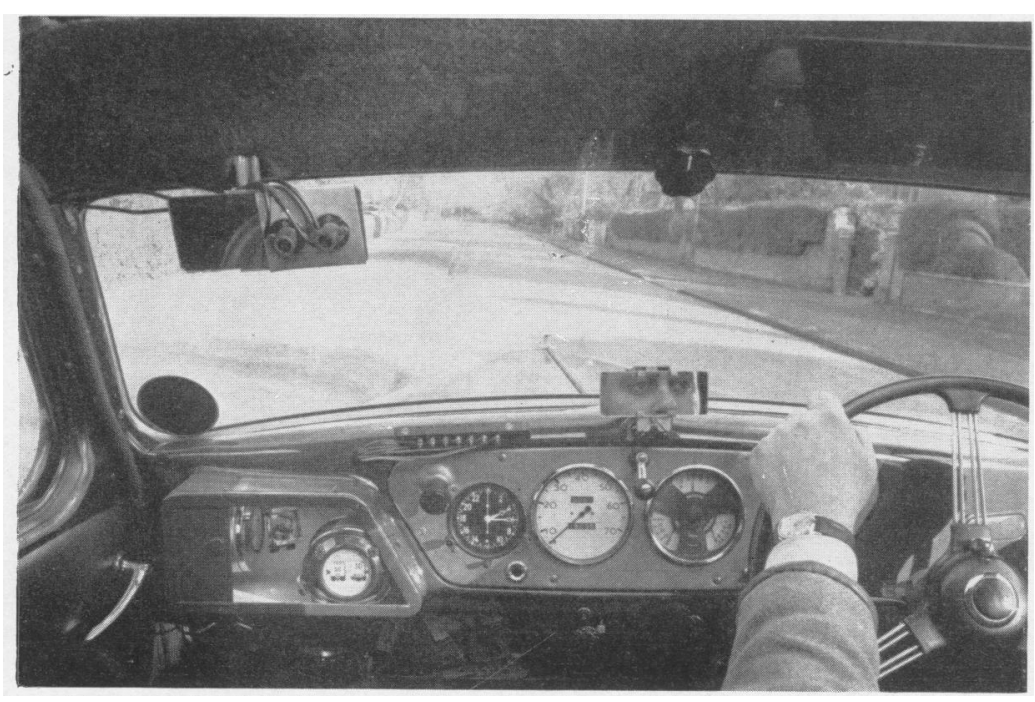

averaged 35 years, and the others 40 years. All the drivers had held a full driving licence for at least three years. At the time of the test the police drivers were driving more regularly than the other men.

Instructions.-Before starting the initial test subjects were briefed on the layout of the experimental car. They were then asked to practise driving the car and to familiarize themselves with the gears, clutch, brake, etc., until they were completely at ease. They then drove to the first corner to be negotiated in the test and parked close to it, in a position allowing a clear view of $(a)$ the approach to the corner, $(b)$ the corner, and $(c)$ the drive away from the corner. The following instructions were then given :-

" The car is now pointing in the direction from which you will start your drive. You have a half-mile approach to this corner along the $15 \mathrm{ft}$. straight lane. The corner you see clearly marked by posts is rather sharp. I would like you to drive comfortably, approach the corner, turn it, and then drive away. You must keep within the limits of the $15 \mathrm{ft}$. road. Some distance after the corner there is another exactly the same. Turn this also and then after you have driven away from it I will tell you where to turn around. We then drive back, turning the same corners to the left. Are there any questions?"

Questions were asked by a number of drivers in each group and were answered in full, with the exception of those relating to speed or time allowed; in these cases it was reiterated that the only requirement was to drive " comfortably".

The subject then drove to the starting point for the run (Fig. 1) and began his approach to the first corner.

As the mark 150 yards before the corner was passed, the experimenter seated in the rear nearside passenger seat switched on the camera, which, as stated previously, photographed the road ahead and the instruments once every five yards. At the mark 150 yards after the corner the camera was switched off.

This procedure was repeated for all four corners.

The Retest.-Instructions were repeated for all subjects six weeks later, when exactly the same test was run through again. None of the subjects knew that this repeat run was to be an exact repetition of the first test.

Methods of Analysis. - The film records of acceleration were analysed frame-by-frame and the 61 readings obtained over 300 yards at 5-yard intervals were recorded for each corner.

Use was made of accelerometer readings rather than velocity readings because they reflect more directly what the

FIG. 2.-Photograph by the recording camera. 
subject is doing with the controls, which are acceleration controls rather than direct velocity controls. Therefore these acceleration readings have been adopted although at first sight it might seem that they could have been calculated from the simple velocity-time record.

For each subject it was possible to plot a performance graph for each of four corners for the first occasion of the test ; over this was superimposed the performance graph for the same corner negotiated six weeks later (Fig. 3).

The area difference between these curves was obtained by calculating the sum of the differences between corresponding "5-yard" acceleration scores for the test and retest curves. This sum was taken as the index of lack of consistency. Separate tctals were calculated for the approach half and departure half of each corner. In this way eight inconsistency scores over the six-week period were calculated for each subject. Same-day inconsistency scores were also obtained for both the test and the retest days by comparing the two consecutive curves for the right hand corners and the two consecutive curves for the left hand corners.

\section{Results}

Consistency with the Six-Week Interval.-The performance graphs of all trials made in the course of the experiment are shown in Figs. 5, 6, and 7. Fig. 4 summarizes the evidence.

By analysis of variance the comparison between the three groups showed a highly significant difference between the mean consistency scores for the three groups (Appendix).

Individual comparisons between pairs of groups showed no significant difference between police and rally drivers, but differences between the unskilled

Fig. 3.-Key to miniature graphs (Figs. 5, 6, and 7),

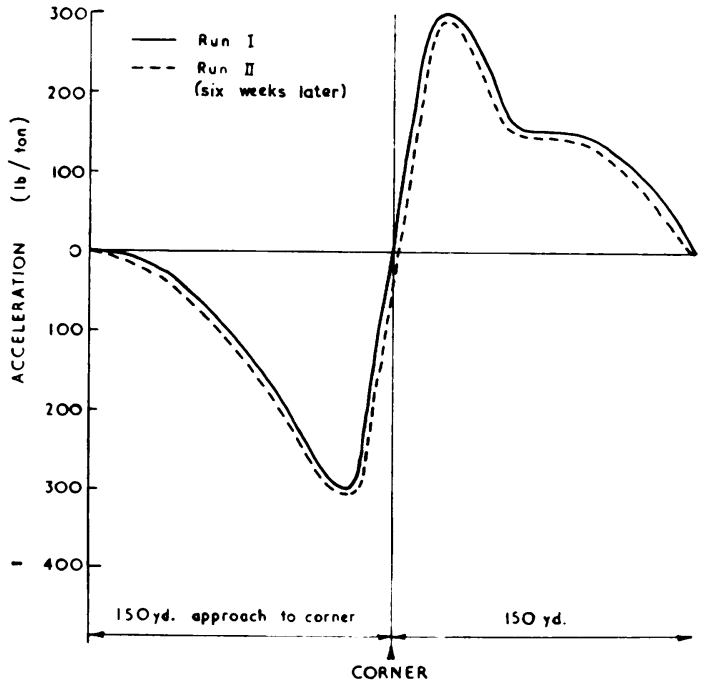

Fig. 4.-Consistency scores for acceleration data from skilled and unskilled drivers.

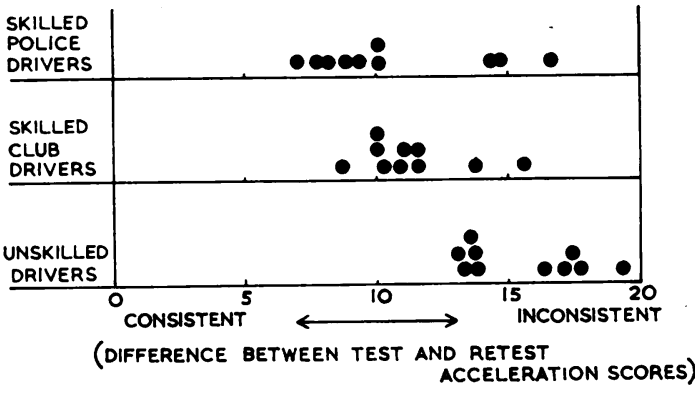

and each of the remaining two groups were found to be significant at the 0.001 level. The mean inconsistency scores for the police, rally, and unskilled groups were 108, 114, and 156 respectively, as will be clear from Table 1 and Fig. 4.

TABLE 1

INDIVIDUAL INCONSISTENCY SCORES

\begin{tabular}{c|c|c}
\hline $\begin{array}{c}\text { Skilled Police } \\
\text { Drivers }\end{array}$ & $\begin{array}{c}\text { Skilled Rally } \\
\text { Drivers }\end{array}$ & $\begin{array}{c}\text { Unskilled } \\
\text { Drivers }\end{array}$ \\
\hline 71 & 87 & 131 \\
79 & 100 & 134 \\
82 & 100 & 136 \\
89 & 102 & 138 \\
93 & 109 & 139 \\
101 & 111 & 163 \\
101 & 116 & 172 \\
145 & 117 & 179 \\
148 & 139 & 194 \\
168 & 156 & 156 \\
\hline
\end{tabular}

The marked difference between individuals in the police group may be attributed to the poor consistency scores of three subjects whose scores departed from the level established by the majority in this group. On the retest these three drivers approached the corners at a very different speed from their speed on the first test, whereas the remaining drivers tended to approach at the same speed on the two occasions.

Consistency for the unskilled group appears from Fig. 6 to be poorer before the corners than after. This result is possibly due to the expected difficulties imposed by the approaching corner. The acceleration curves for the approach vary considerably between and within the drivers in the unskilled group, whereas after the corners the attempts are more homogeneous. No differences between left and right corners were found.

Inconsistency within the Same Day.-A further analysis of variance was carried out on the scores of inconsistency between consecutive corners within one day for the three groups. No statistically signi- 
Corners right
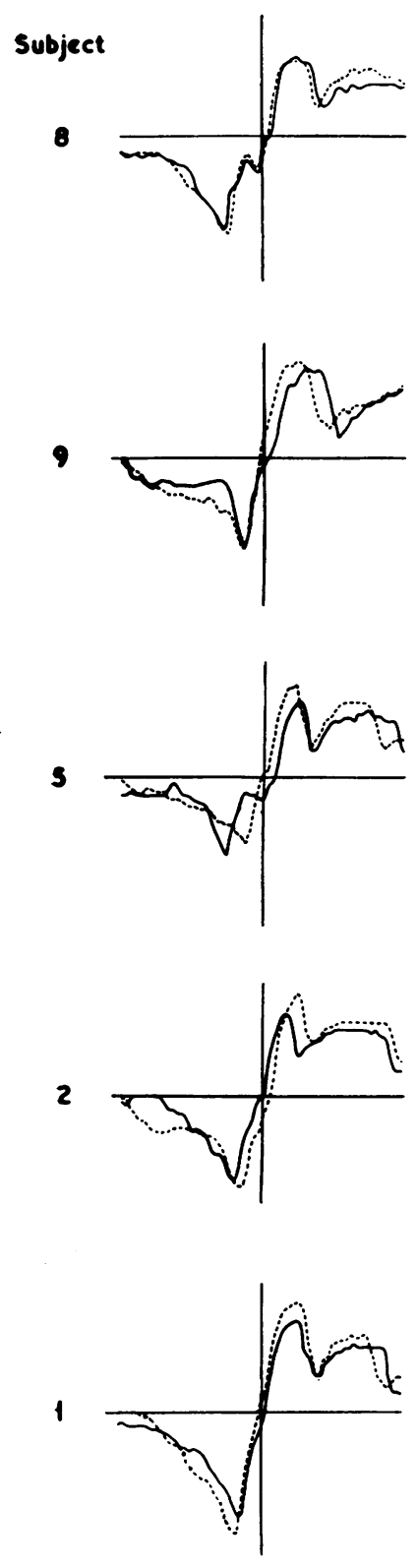
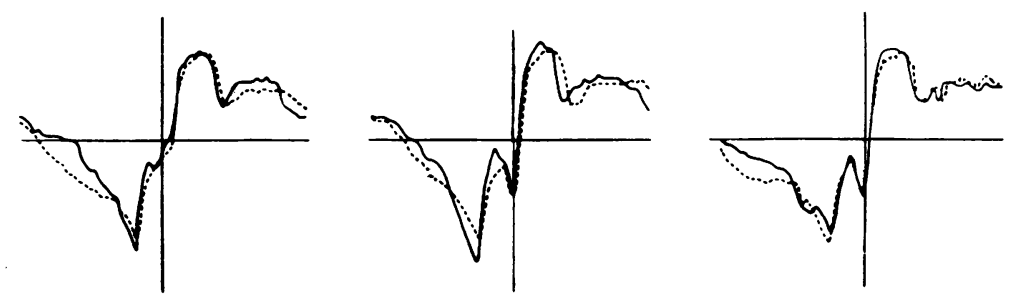

Corners left
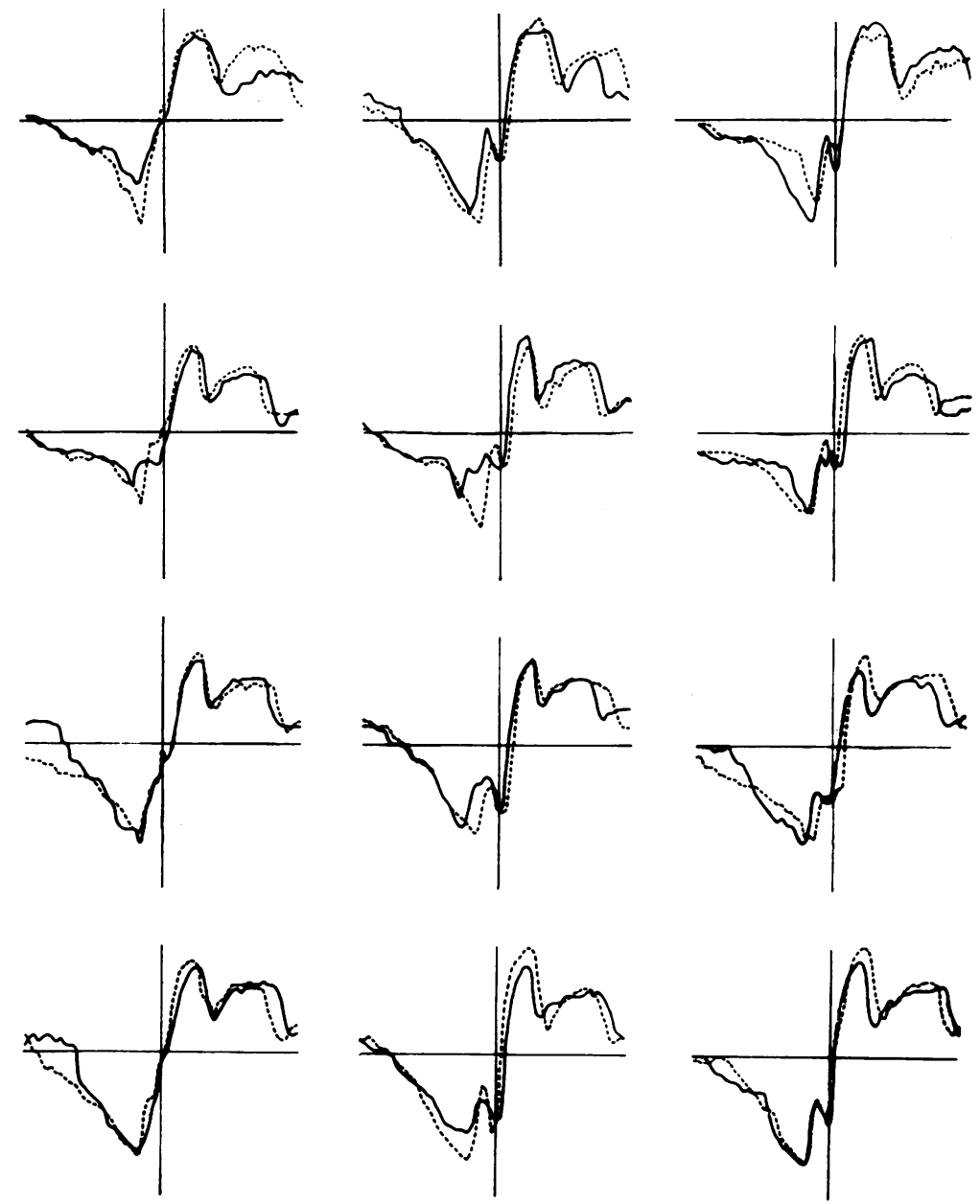

FIG. 5.-Graph of performance of skilled police drivers. 
Corners right

Corners left

Subject
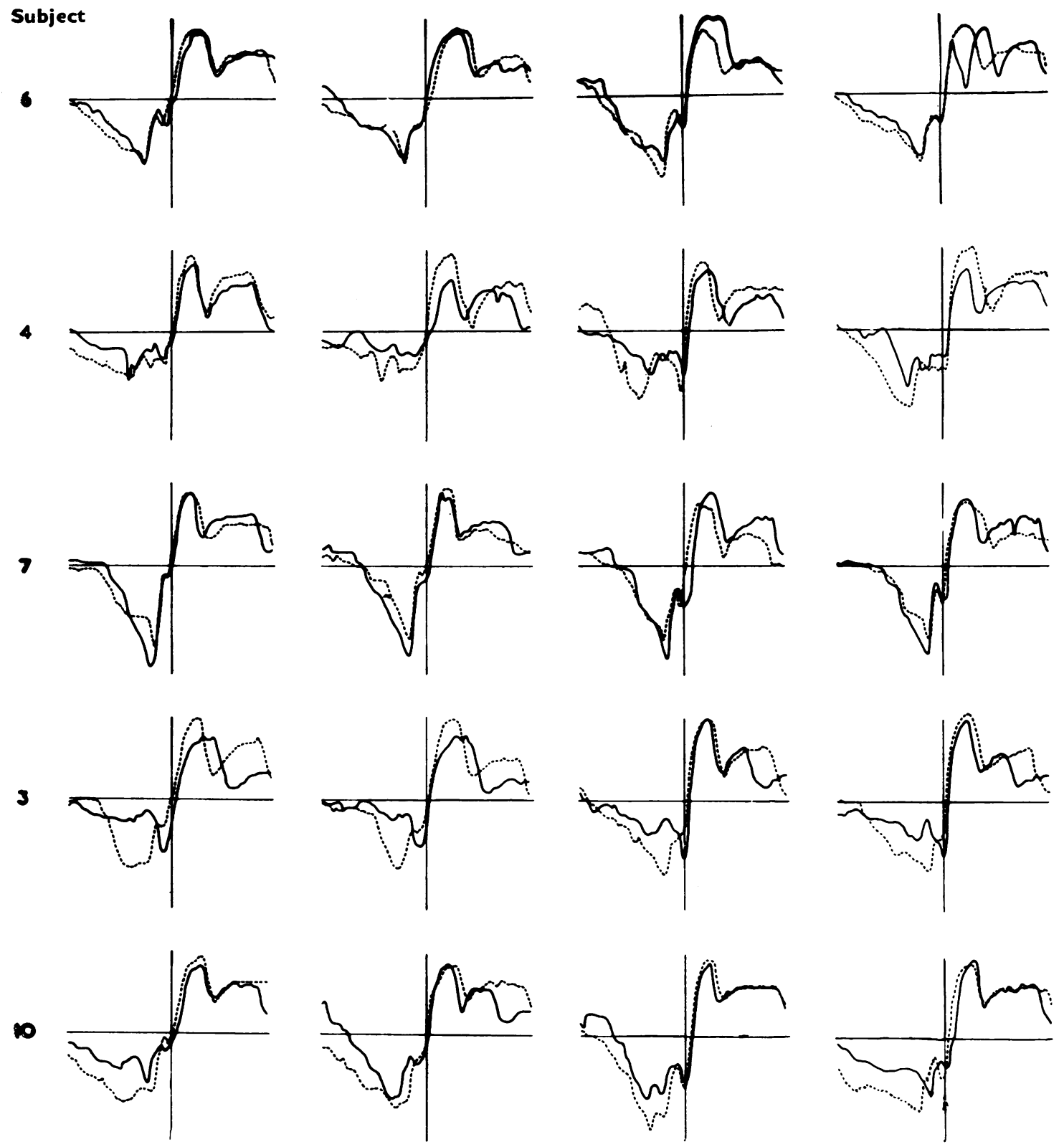

Fig. 5.-continued.
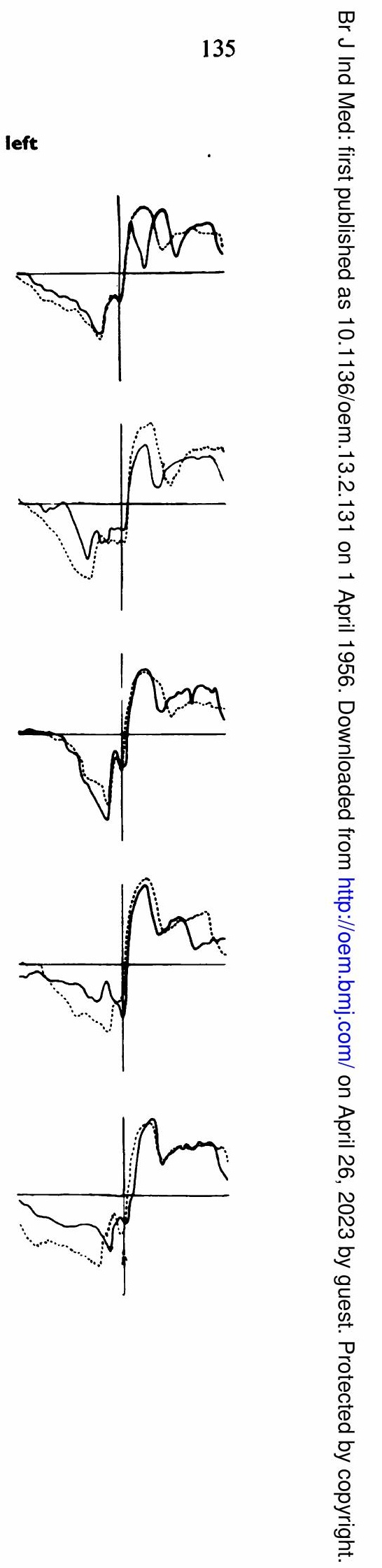
Corners right
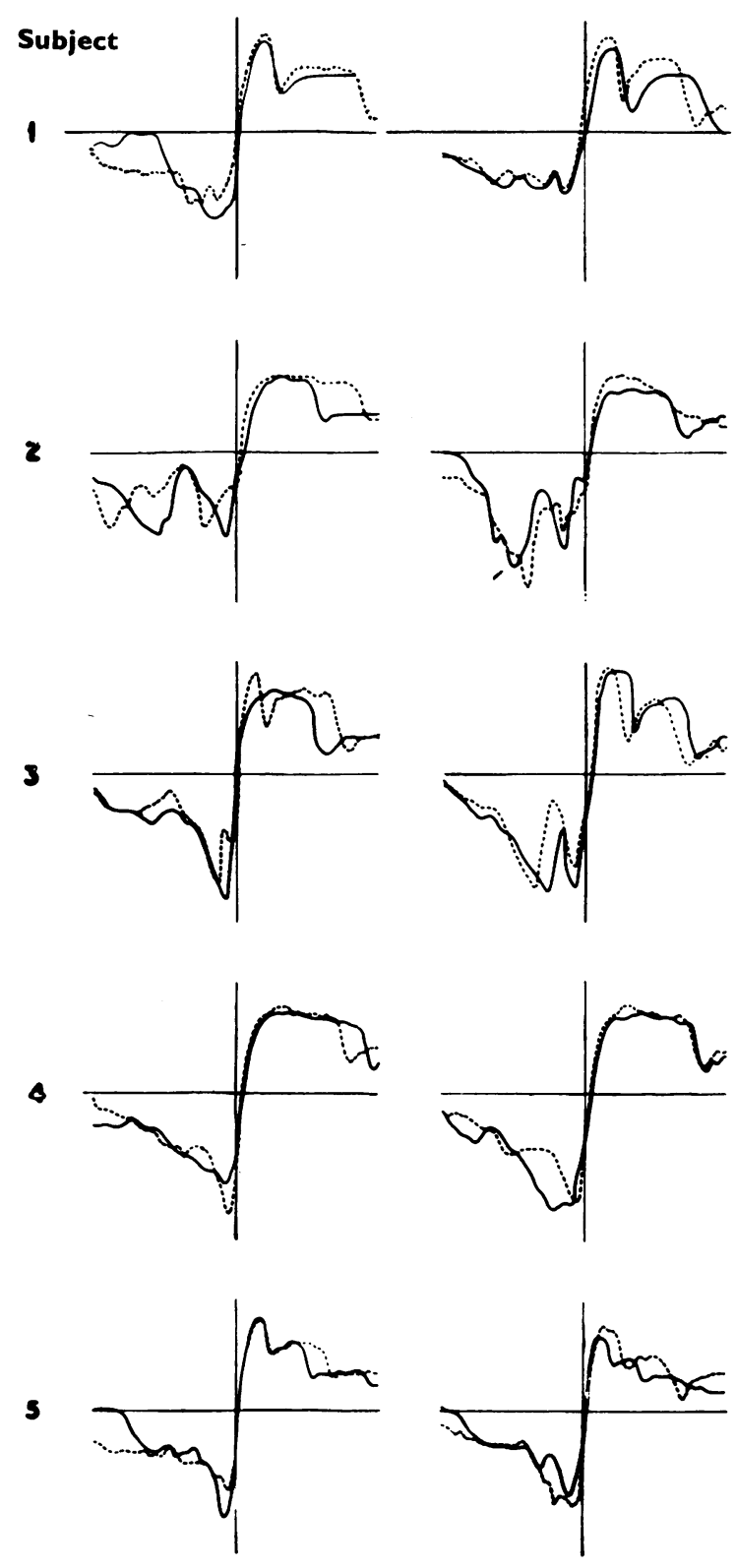

Corners left
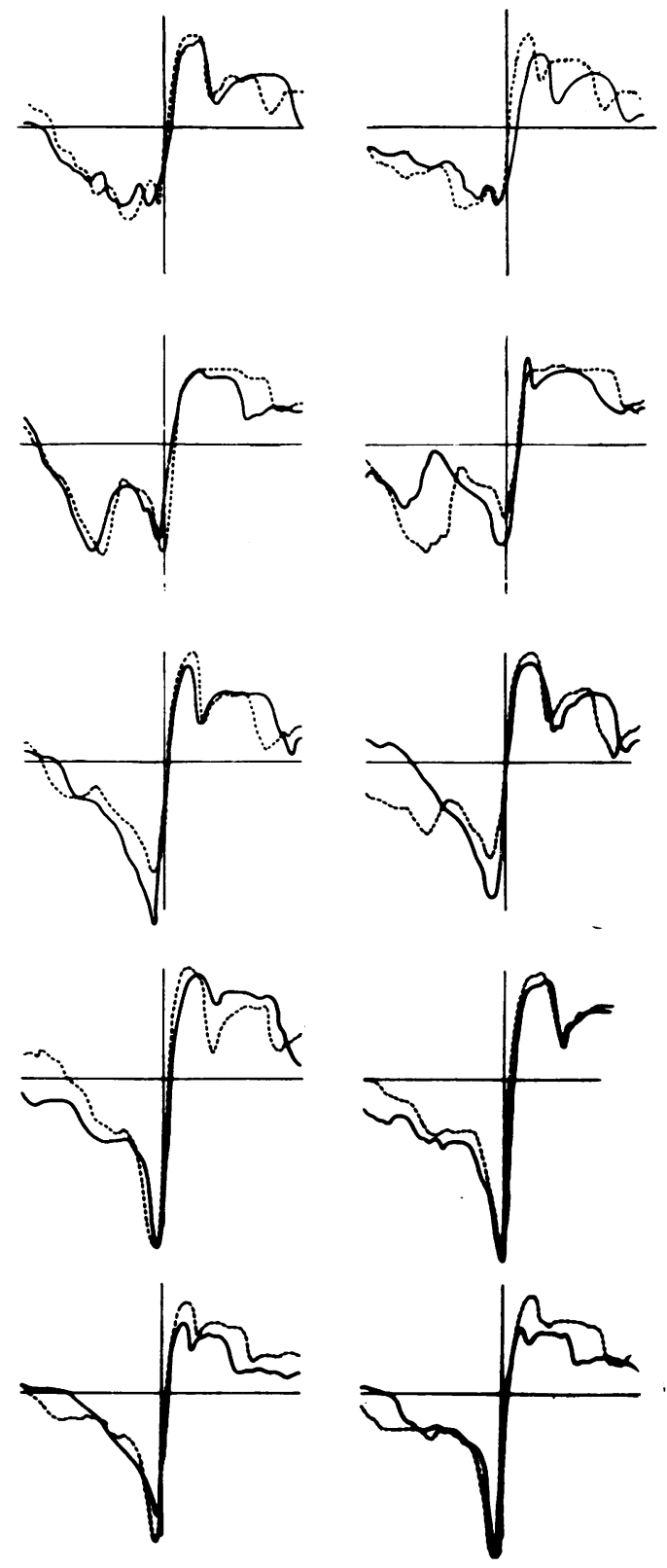

FIG. 6.-Graph of performance of skilled rally drivers. 

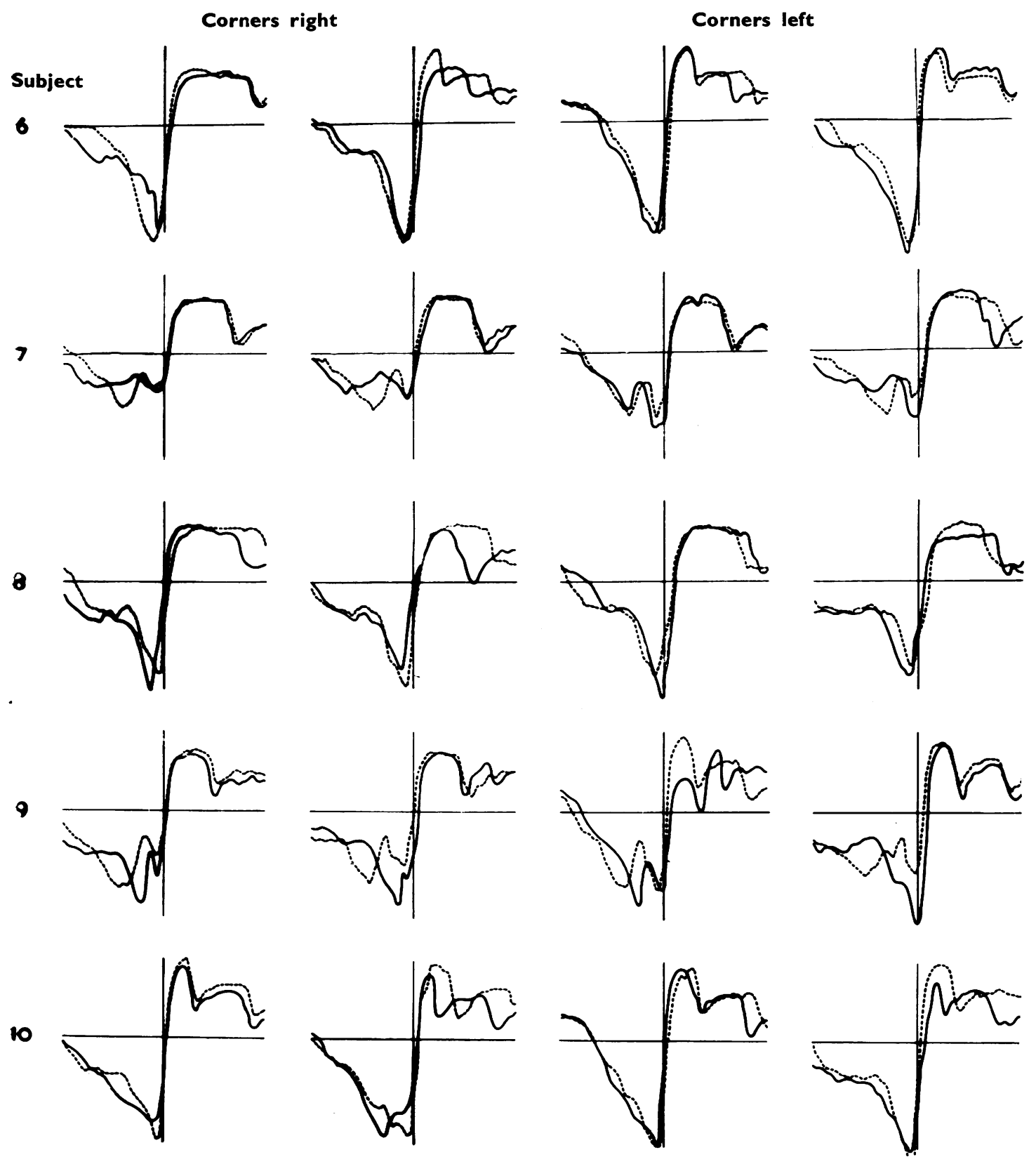

FIG. 6.-continued.

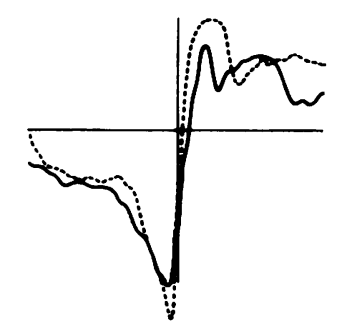


Corners right

Corners left

Subject
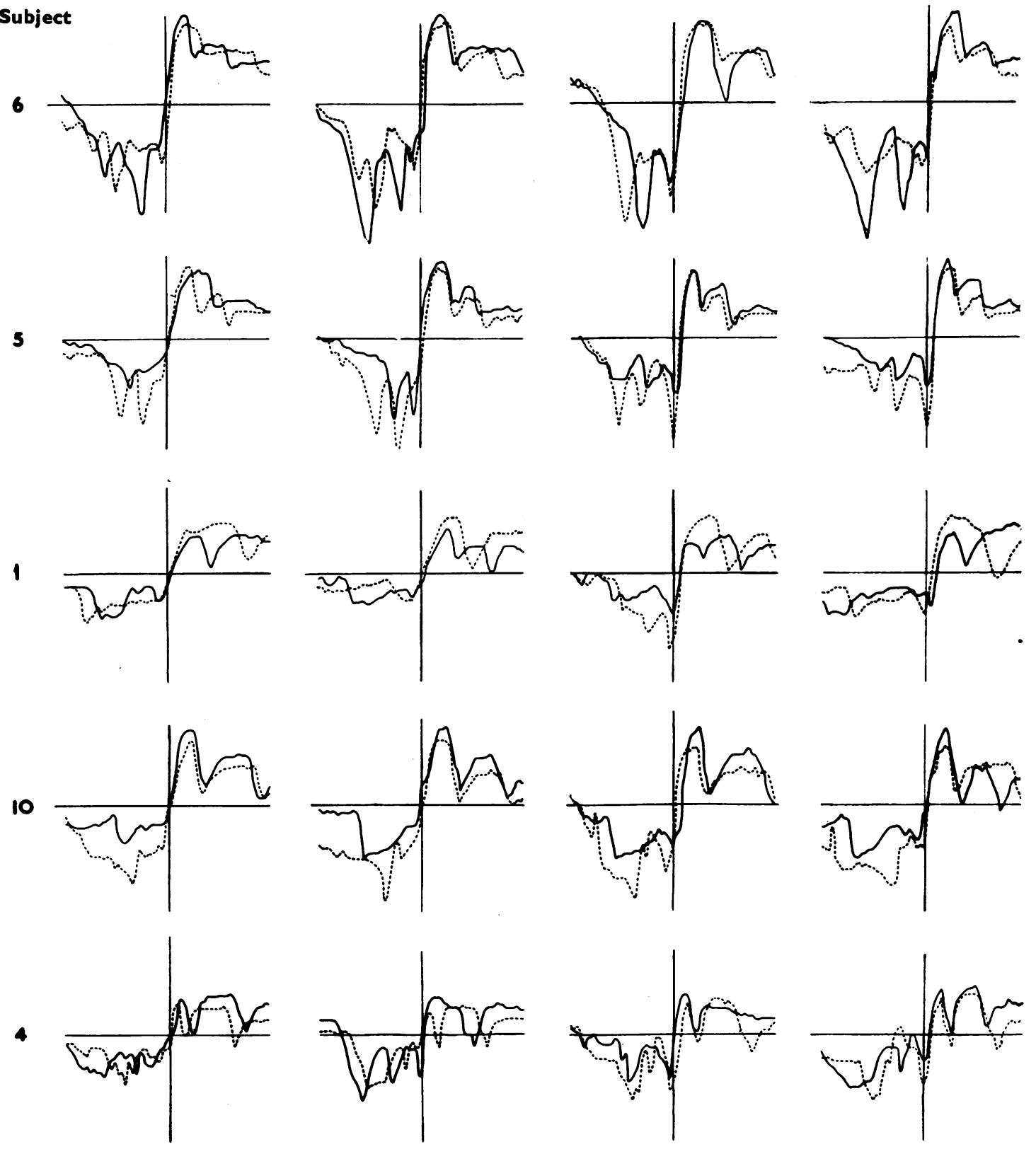

FIG. 7.-Graph of performance of unskilled drivers. 
Corners right

Corners left

Subject
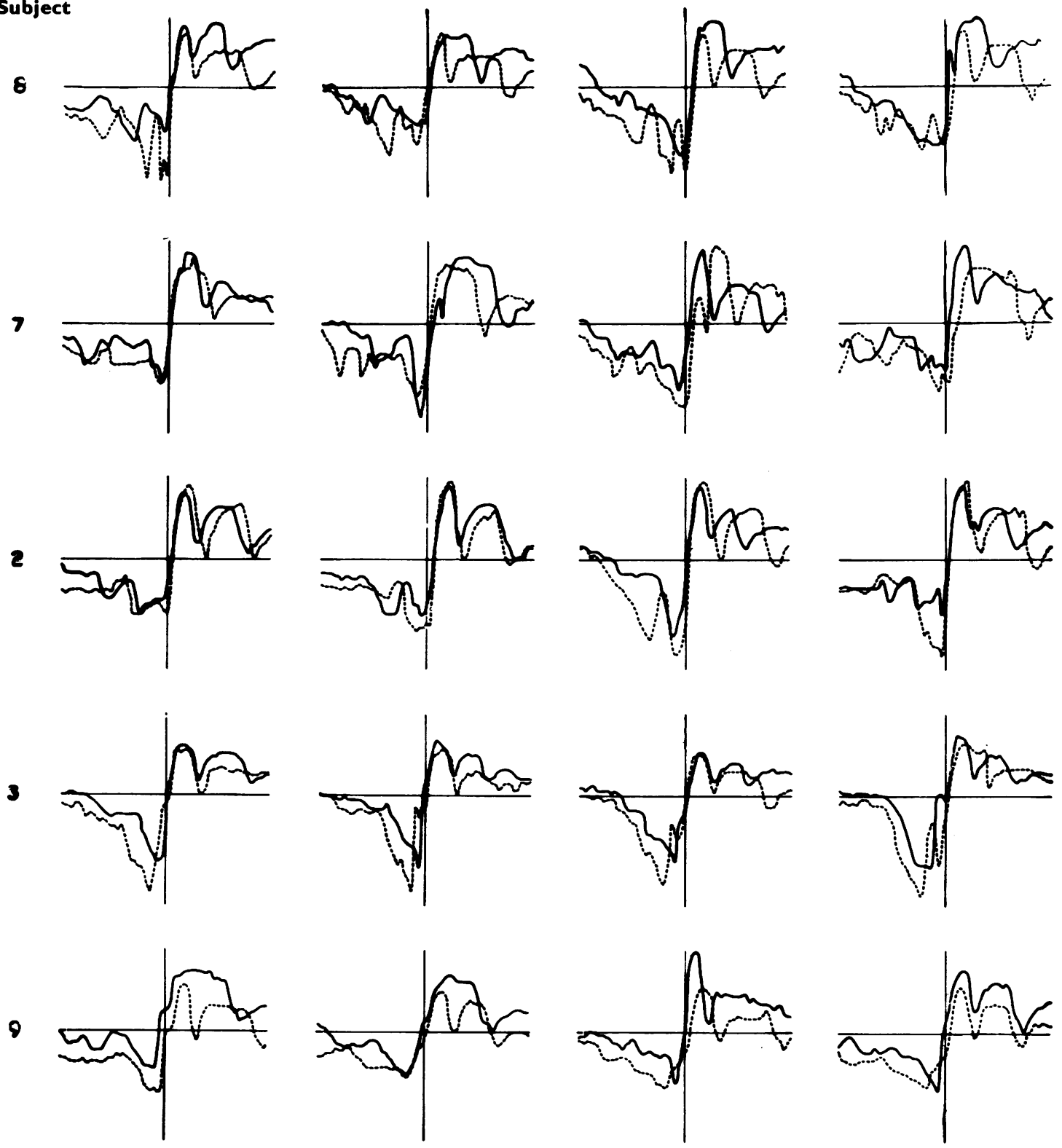

FIG. 7.-continued 
ficant differences were found between groups although the unskilled drivers still appeared to be the least consistent. In spite of the fact that they seemed at times to repeat their mistakes, e.g., misjudgment of deceleration requirements before the corner, the differences between test and retest were higher than those of the other drivers, because they often made the same mistakes at different stages in the approach to the corner.

The police and unskilled groups showed a significantly lower inconsistency score within the same day than when a six-week interval elapsed between test and retest (Table 2). The tendency

TABLE 2

MEAN SCORES OF INCONSISTENCY

\begin{tabular}{lll|c|c}
\hline \multicolumn{1}{c|}{ Group } & & & Same Day & Six Weeks \\
\hline Skilled police drivers &. & $\ldots$ & 91 & 108 \\
Skilled rally drivers &. & $\ldots$ & 107 & 114 \\
Unskilled drivers &. &. & 120 & 156 \\
\hline
\end{tabular}

was apparently the same for the skilled rally drivers, but this was not a reliable statistical difference.

\section{Discussion}

The changes in behaviour occurring with different time intervals between test and retest are not easily explained. There are many factors likely to change behaviour when response is made to identical stimuli and the time interval between test and retest is great. In this experiment we have disregarded the conditions and stresses of life to which all our subjects were exposed during the six-week interval between test and retest. In spite of this we have found that over this period the behaviour of skilled drivers during cornering trials was little changed. It was surprising how consistent a really skilled man could be in these circumstances. It appears that what happens to a skilled man between tests may have little effect on his performance in a wellestablished skill. It has been shown by Tillmann and Hobbs (1949) in work on the accident-prone driver that living habits are associated with vehicle driving performance. The statement "we drive as we live" may well be true, for daily examples can be seen of personality reflected in performance in skill and sport.

The personality of the drivers who acted as subjects for this experiment was examined by Venables (1955) who gave tests to a number of drivers in each of the three groups. These tests sought neurotic or anxiety-hysteria traits. The main differences between groups indicated that the scores of the police and rally groups all lay within the normal range ; in the unskilled group, four of the six scores obtained were tending toward the neurotic end of the scale. This suggested some relationship between lack of consistency in testretest scores and neurotic personality ; but it must not be supposed that any such relationship can be regarded as established.

Though the main differences between groups in the actual driving trials were in terms of consistency, interesting differences were also observed in the acceleration patterns. Clear differences were found between groups in the manner in which corners were approached (see Figs. 5, 6, and 7). The police group appeared to decide to decelerate from a point about 150 yards from the corner. The deceleration generally continued smoothly until a peak deceleration was reached and the car was then accelerated around and away from the corner. This procedure was usual with most of the police group (Fig. 5) and probably reflected the standard training methods of the police driving schools. The rally group differed between themselves, although in general they have approach patterns similar to those of the police. These differences between rally drivers may have resulted from varying methods of instruction. The unskilled group (Fig. 7) show frequent reversals in their approach acceleration patterns, perhaps due to their inability to make correct decisions when confronted with the approaching corner. This demonstrates clearly the role of anticipation in skill as discussed by Oldfield (1952).

Though interesting, these single trial patterns do not lend themselves conveniently to any analysis that seeks to distinguish between groups of skilled and unskilled drivers, for some of the unskilled drivers do not show reversals but are nevertheless inconsistent. It is here that the possible value of consistency measures lies, for this technique enables an estimate to be made of a man's performance against his own standards.

Thus consistency measures may be related to the level of experience or training. It is also possible that if examined from the consistency viewpoint, measures of performance might be of value at an early stage in training in predicting the eventual level of skill likely to be achieved. In conclusion, there would seem to be many further applications of the consistency measure that could be made in the course of experiments dealing with fatigue, stress, and ageing. The optimum test-retest interval will presumably vary with the test and should be determined in each case.

\section{Summary}

The paper considers whether consistency in performance between two occasions of test separated 
by a six-week interval is related to skill in driving. Evidence is presented which suggests the value of this approach to measuring skill; the general importance of the finding is that this method of assessment can be used even in cases where there are many different ways of doing the given task.

Cornering trials were performed by three groups of drivers on an aerodrome without any traffic. The comparisons were between (a) skilled police drivers, (b) skilled rally drivers who had been given no standard training, and (c) unskilled drivers. The skill of these 30 drivers was assessed by the same chief police driving instructor and the three groups were made up for study according to his views.

After a great deal of trial and error it was found that the most promising measure was that of vehicle acceleration and deceleration. Readings of acceleration/deceleration were therefore recorded photographically every 5 yards over a distance of 150 yards before and after each of the four corners in the test run. An exactly similar run was given six weeks later to the same $\mathbf{3 0}$ drivers.

Scores of consistency were calculated for each subject over the six-week interval and it was found that those in both skilled groups, police-trained and self-trained, were significantly more consistent than were the unskilled drivers.

Although test-retest consistency gave differences between the three groups when test and retest were separated by an interval of six weeks, the same group differences in consistency did not show when consistency between consecutive corners was considered within the same day. The optimum testretest interval to reveal the differences between good and bad drivers clearly needs further detailed consideration.

This work was carried out under the direction and guidance of Sir Frederic Bartlett, F.R.S., and Dr. N. H. Mackworth. Mr. Eric Farmer initiated this series of experiments whilst Chairman of the Road User Committee. The staff of the Road Research Laboratory has also given assistance.

Miss Violet Cane advised on statistical problems and directed Mr. Goodhardt in his work on the complete statistical analysis.

It is a pleasure to thank Captain Peel, Chief Constable of the Essex County Constabulary, for the facilities he provided, and Inspector F. R. Priestley, the Chief Driving Instructor of the Essex County Police Advanced Driving School, who spared no effort in ensuring that the experiment proceeded smoothly.

Messrs. Co-Partnership Farms Limited, Boreham, were kind enough to allow us to use their airfield.

Finally, I wish to thank the 30 drivers, police and civilian, who drove so keenly as subjects and made the experiment possible.

\section{REFERENCES}

Ashby, W. Ross (1952). Design for a Brain, p. 148. Chapman \& Hall, London.

Bartlett, F. C. (1947). Brit. med. J., 1, 835.

Bartlesi). Research, 4, 217.

Lashley, K. S. (1951). In Cerebral Mechanisms in Behaviour, p. 118. The Hixon Symposium, ed. L. A. Jeffress. Wiley, New York.

Oldfield, R. C. (1952). New Biologv, 13, 49.

Tillmann, W. A., and Hobbs, G. E. (1949). Amer. J. Psychiat., 106, 321.

Venables, P. (1956). J. appl. Psychol. To be published. 